\title{
Tromboembolismo Pulmonar em um Paciente Jovem com COVID-19 Assintomático
}

\author{
Pulmonary Thromboembolism in a Young Patient with Asymptomatic COVID-19
}

\author{
Nicolas H. Borges, ${ }^{1}$ Thiago M. Godoy, ${ }^{1}$ Marcos Roberto Curcio Pereira, ${ }^{1}$ Rebecca B. Stocco, ${ }^{1}$ Viviane Maria de \\ Carvalho Hessel Dias, ${ }^{1,2}$ Cristina Pellegrino Baena, ${ }^{1,2}$ Gustavo Lenci Marques ${ }^{1,2}$ \\ Pontifícia Universidade Católica do Paraná, ${ }^{1}$ Curitiba, PR - Brasil \\ Hospital Marcelino Champagnat, ${ }^{2}$ Curitiba, $P R$ - Brasil
}

\section{Apresentação de Caso}

Paciente do sexo masculino, 22 anos, sem comorbidades prévias e uso de medicamentos, foi encaminhado ao nosso hospital em 24/06/2020. Sem sintomas, em 12/06/2020 foi diagnosticado com COVID-19 após um teste de triagem por PCR exigido em sua empresa, e permaneceu em repouso no leito durante a maior parte de seu isolamento. Permaneceu assintomático por 11 dias, porém, em 24/06/2020, deu entrada no pronto-socorro com dor ventilatório-dependente em hemitórax direito. Os sinais vitais revelaram hipertensão (132/78 mmHg), taquicardia (127 bpm), hipóxia $\left(\mathrm{SpO}_{2}\right.$ de $90 \%$ em ar ambiente) e febre $\left(38,7^{\circ} \mathrm{C}\right)$. Ao exame físico, chamou a atenção a diminuição dos sons respiratórios em hemitórax direito durante a ausculta pulmonar. Os escores de estratificação de risco de Pádua e Wells foram aplicados, e os critérios indicaram um risco baixo (3 pontos) e um risco moderado (6 pontos), respectivamente. D-dímero $(6,652$ $\mu \mathrm{g} / \mathrm{L}$ ), Proteína C-Reativa (94 mg/L) e Troponina (119pg/ $\mathrm{mL}$ ) estavam entre os testes laboratoriais realizados. Foi solicitada uma tomografia computadorizada (TC) de tórax (Figura 1), que demonstrou a Corcova de Humpton. uma opacificação de base pleural no pulmão, mais comumente decorrente de embolia pulmonar. Além disso, também foram encontradas opacidades pulmonares em consolidação e áreas de opacidade em vidro fosco periféricas, multifocal e bilateral, associadas a espessamento septal, com pequena área de consolidação entre elas, mais acentuada no lobo inferior direito e com envolvimento pulmonar moderado (25-50\%).

Em 25/06/2020, foi solicitada uma tomoangiografia pulmonar (angioTC) (Figura 2), que evidenciou defeitos de enchimento nas artérias pulmonares bilateralmente, com extensão para seus ramos superior, médio e lingual, compatível com quadro agudo maciço condição de tromboembolismo pulmonar. O paciente foi encaminhado em 25/06/2020 para

\section{Palavras-chave}

SARS-CoV-2; Jovem; Tromboembolismo Pulmonar; Tríade de Virchow; COVID-19, Coronavirus-19, Assintomático.

Correspondência: Cristina Pellegrino Baena •

Pontifícia Universidade Católica do Paraná - Rua Imaculada Conceição,

1155. CEP 80215-901, Prado Velho, Curitiba, PR - Brasil

E-mail: cbaena01@gmail.com

Artigo recebido em 29/08/2020, revisado em 02/09/2020, aceito em $30 / 09 / 2020$

DOI: https://doi.org/10.36660/abc.20200957 a Unidade de Terapia Intensiva (UTI), hemodinamicamente estável, sendo solicitada a coleta do material de swab nasal e de orofaringe para SARS-CoV-2, o qual apresentou diagnóstico positivo em 26/06/2020. O tratamento foi iniciado com Ceftriaxona ( $2 \mathrm{~g}$ ao dia), Azitromicina (500mg ao dia), Dexametasona (6mg ao dia) e Oseltamivir ( $75 \mathrm{mg}$ ao dia), associado à Enoxaparina (80mg ao dia) para profilaxia da trombose venosa. O paciente evoluiu com melhora progressiva. Ele teve alta da UTI para a enfermaria em 28/06/2020 e alta hospitalar definitiva em 29/06/2020, em uso de rivaroxabana (15mg BID), sendo encaminhado para futura reavaliação ambulatorial.

Após a alta, foram solicitados exames para investigação de trombofilia, incluindo: Proteína $S$ funcional, Proteína C funcional, Homocisteína, Fator $\mathrm{V}$ de Leiden, Mutação do gene da protrombina, Antitrombina III, Anticoagulante Lúpico e Anticardiolipina IgM. Destacam-se o aumento da Antitrombina III (999\%), a fraca presença do Anticoagulante Lúpico $(1,43)$ e os níveis indeterminados de Anticardiolipina IgM. Além disso, foram solicitadas ecocardiografia e ultrassonografia Doppler de membros inferiores, ambas dentro dos padrões de normalidade, afastando possíveis sinais de trombose, recente ou tardia.

\section{Discussão}

Muitos pacientes com COVID-19 têm anormalidades de coagulação que mimetizam outras coagulopatias sistêmicas associadas a infecções graves, como coagulação intravascular disseminada ou microangiopatia trombótica. ${ }^{1}$ A coagulopatia resultante da COVID-19 pode ocorrer tanto na circulação venosa quanto arterial e está associada à liberação de citocinas pró-inflamatórias, como (IL-2, IL6, IL-7, IL-10). ${ }^{2}$ Os achados dos estudos mais recentes são consistentes com a estreita ligação entre trombose e inflamação, dois processos que reforçam um ao outro, pois durante a infecção por SARSCoV-2, o endotélio é capaz de mudar para um fenótipo inflamatório responsivo após sua ativação, expressando citocinas e moléculas de adesão vascular, o que pode agravar ainda mais a tempestade de citocinas.

Essas citocinas, por sua vez, podem causar disfunções do glicocálice presente nas células endoteliais, responsáveis por criar uma barreira contra a agregação de plaquetas e células sanguíneas, contribuindo para o desenvolvimento de eventos trombóticos e endoteliais. Além disso, o estado inflamatório sistêmico também resulta em disfunção endotelial, induzindo as células afetadas a um processo de morte celular denominado piroptose. ${ }^{3}$ Todas essas alterações na resposta 


\section{Relato de Caso}

pró-inflamatória do hospedeiro, além da disfunção endotelial, também implicam em um amplo desarranjo em diversos parâmetros de hemostasia, entre os quais D-dímero, ${ }^{4}$ que é um potencial marcador de prognóstico e / ou mortalidade em pacientes acometidos pela doença. ${ }^{5}$

Apesar de não apresentar fatores de risco para complicações, o paciente deste relato desenvolveu TEP agudo maciço. Isso poderia ser explicado a partir da teoria da Tríade de Virchow, onde a disfunção endotelial, estase e hipercoagulabilidade sanguínea convergem para o desenvolvimento de processos trombóticos, entre eles, destaca-se o tromboembolismo pulmonar. O estado de hipercoagulabilidade e disfunção endotelial pode ser justificado devido à infecção viral que se refletiu em uma alteração importante no nível sérico de D-dímero (6652 $\mu \mathrm{g}$ / L), que está associado a uma maior gravidade da COVID-19; além disso, o paciente relatou que, após o diagnóstico de COVID-19, permaneceu deitado, em repouso no leito em sua residência, o que corrobora a presença de estase sanguínea pulmonar. As recomendações de isolamento pós-diagnóstico também devem ter como objetivo evitar situações que influenciem a estase sanguínea.

\section{Contribuição dos autores}

Concepção e desenho da pesquisa, Obtenção de dados, Análise e interpretação dos dados, Análise estatística,
Redação do manuscrito e Revisão crítica do manuscrito quanto ao conteúdo intelectual importante: Borges $\mathrm{NH}$, Godoy TM, Curcio M, Stocco RB, Hessel V, Baena CP, Lenci G

\section{Potencial conflito de interesses}

Declaro não haver conflito de interesses pertinentes.

\section{Fontes de financiamento}

O presente estudo não teve fontes de financiamento externas.

\section{Vinculação acadêmica}

Não há vinculação deste estudo a programas de pósgraduação.

\section{Aprovação ética e consentimento informado}

Este estudo foi aprovado pelo Comitê de Ética da Pontifícia Universidade Católica do Paraná sob o número de protocolo 30188020.7.1001.0020. Todos os procedimentos envolvidos nesse estudo estão de acordo com a Declaração de Helsinki de 1975, atualizada em 2013. O consentimento informado foi obtido de todos os participantes incluídos no estudo.

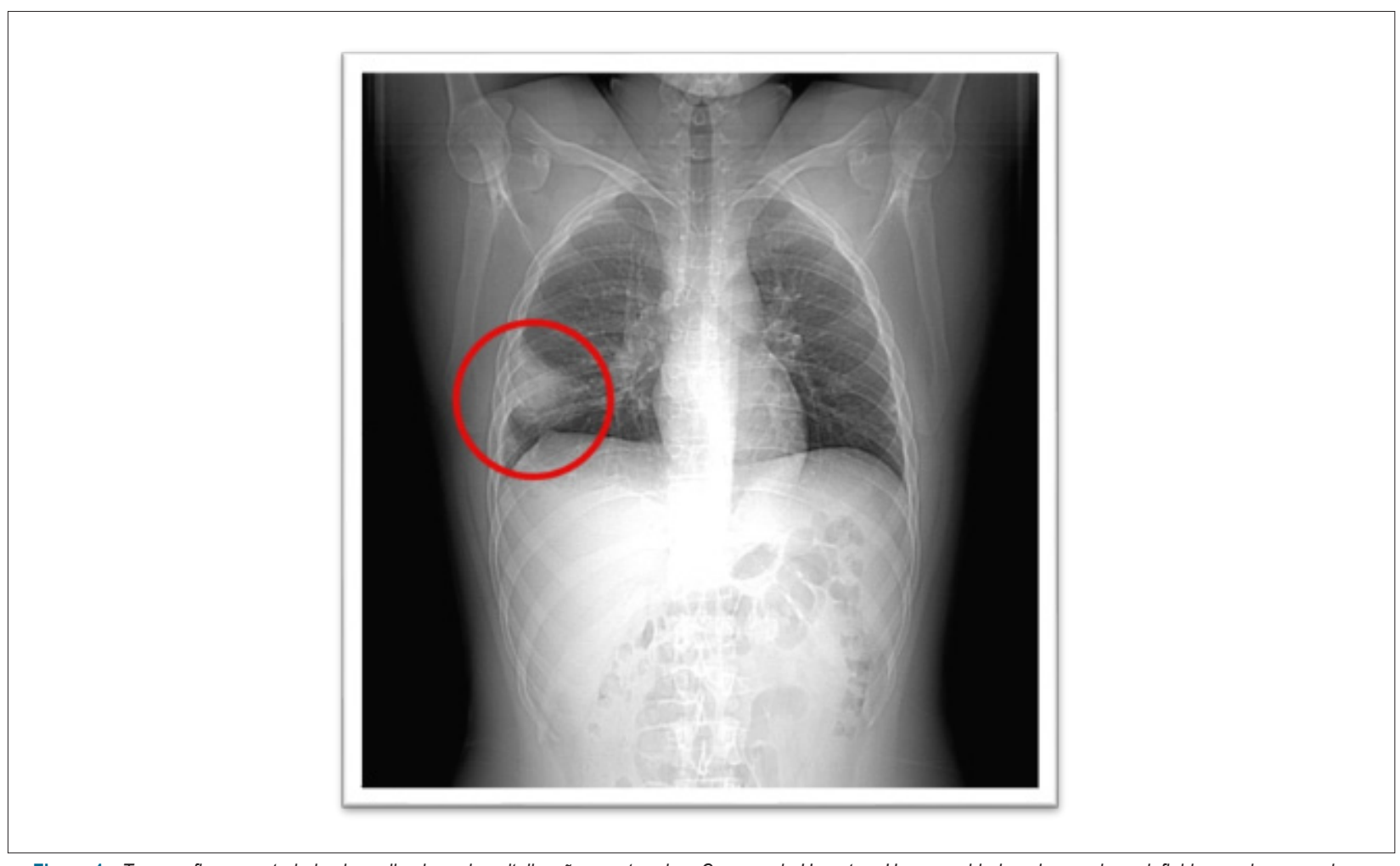

Figura 1 - Tomografia computadorizada realizada na hospitalização, mostrando a Corcova de Humpton. Uma opacidade pulmonar bem definida com base na pleura que representa hemorragia e tecido pulmonar necrótico em uma região de infarto pulmonar causado por embolia pulmonar aguda. 


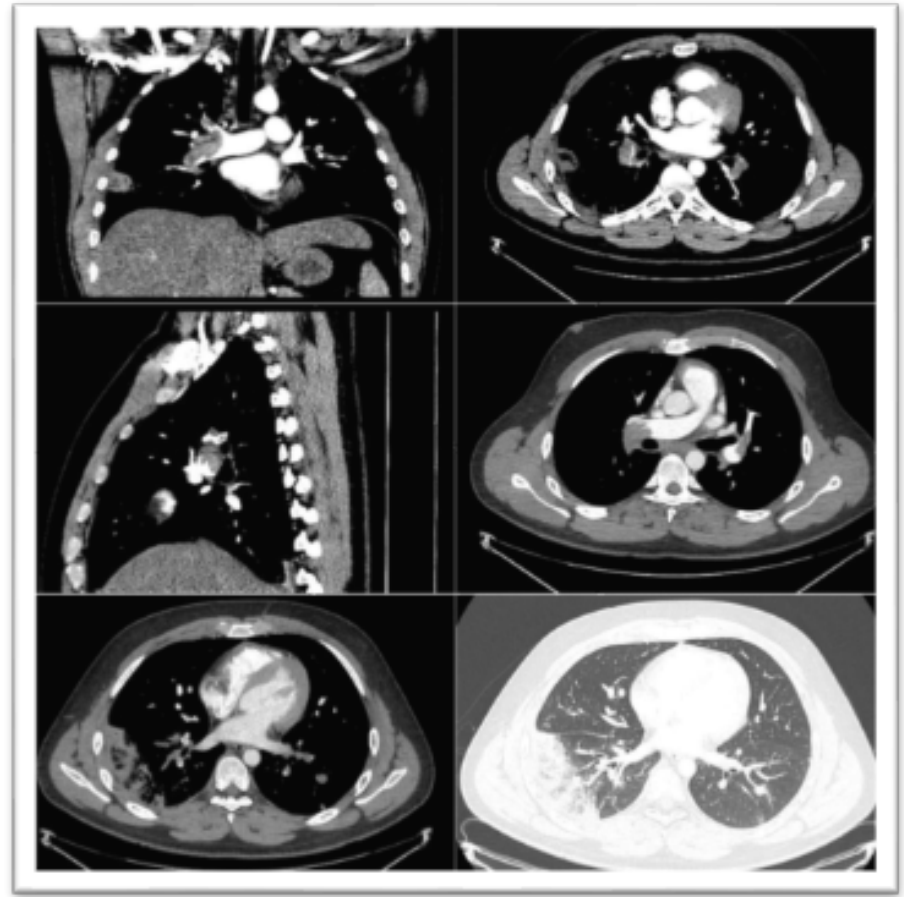

Figura 2 - AngioTC pulmonar realizada no segundo dia, demonstrando defeitos de enchimento nas artérias pulmonares bilateralmente, reforçando o diagnóstico de tromboembolismo pulmonar agudo maciço.

\section{Referências}

1. Levi M, Thachil J, Iba T, Levy JH. Coagulation abnormalities and thrombosis in patients with COVID-19. Lancet Haematol. 2020;7(6):e438-e440.

2. Song P, Li W, Xie J, Hou Y, You C. Cytokine storm induced by SARS-CoV-2. Clin Chim Acta. 2020;509:280-7.

3. Nagashima S, Mendes MC, Martins APC, Borges NH, Godoy TM, Miggiolaro AFRS, et al. Endothelial Dysfunction and Thrombosis in Patients With COVID-19. Arterioscler Thromb Vasc Biol. 2020;40(10):2404-7.
4. Lippi G, Favaloro EJ. D-dimer is Associated with Severity of Coronavirus Disease 2019: A Pooled Analysis. Thromb Haemost. 2020;120(5):876-8.

5. Favaloro EJ, Lippi G. Recommendations for Minimal Laboratory Testing Panels in Patients with COVID-19: Potential for Prognostic Monitoring. Semin Thromb Hemost. 2020;46(3):379-82. 